\title{
Incentivos por meio de alíquotas seletivas de IPVA para veículos automotores movidos a combustível de menor impacto ambiental
}

\author{
Althair Ferreira dos Santos Junior ${ }^{1}$ \\ Marlene Kempfer Bassoli ${ }^{2}$
}

\begin{abstract}
Resumo
No regime jurídico-constitucional inaugurado em 1988, assegurou-se a todos 0 direito ao meio ambiente equilibrado, reputado como essencial à sadia qualidade de vida, nos termos do Art. 225, impondo à coletividade e ao Estado o dever de defendê-lo e preservá-lo. A Lei Maior da República Federativa contém outros dispositivos que expõem o dever de preservar o meio ambiente, como o Art. 170, $\mathrm{VI}$, dirigido à Ordem Econômica Nacional, legitimando o Estado a intervir no Domínio Econômico por meio normativo e de incentivo (Art. 174 da CF). Ao recorrer ao incentivo, os governos criam normas tributárias que induzem seus destinatários a condutas que contribuam para a redução na emissão de gases poluentes na atmosfera. Neste sentido, a instituição de alíquotas diferenciadas de IPVA (Art. 155, $\S 60$, II, da CF), para veículos que causam menor impacto ambiental, configura-se a intervenção estatal por meio da tributação como um importante instrumento na busca pela efetivação do desiderato constitucional de proteção e preservação do M eio Ambiente.
\end{abstract}

Palavras-Chave: Estado; M eio-Ambiente; Intervenção sobre a Ordem Econômica; Incentivos Fiscais; seletividade no IPVA.

\section{Introdução}

Este trabalho tem por finalidade concatenar os estudos realizados ao longo Projeto de Pesquisa "Estado e Relações Empresariais: Diálogos Filosóficos e Jurídicos diante da Regulação Estatal sobre a Ordem Econômica Nacional" - vinculado ao Programa de Mestrado da Universidade Estadual de Londrina, e coordenado pelos professores Drs. Elve Miguel Cenci, Bianco Zalmora Garcia, Clodomiro José Bannwart e pela professora Drạ. Marlene Kempfer Bassoli - com a temática proposta no último bimestre da Disciplina de

\footnotetext{
${ }^{1}$ Acadêmico do 5o ano do Curso de Direito da Universidade Estadual de Londrina; membro participante do Projeto de Pesquisa "Estado e Relações Empresariais: Diálogos Filosóficos e Jurídicos diante da Regulação Estatal sobre a Ordem Econômica Nacional" do Departamento de Direito Público da UEL;

2 Doutora e mestra em Direito do Estado pela PUC/SP, professora da graduação, especialização e mestrado na UEL, UNIM AR-SP e PUC-PR; coordenadora do referido Projeto de Pesquisa.
} 
Direito Tributário (IPVA), ministrada pela referida professora ao 50 ano do Curso de Direito da mesma Universidade.

Por meio deste desafio tem-se a rica oportunidade de lançar mão dos conceitos estudados durante os três anos em que se desenvolveu o referido Projeto de Pesquisa, relativamente à intervenção do Estado sobre o Domínio Econômico, perscrutando alternativas de aplicação dos expedientes interventivos previstos na Constituição da República e colocados à disposição do Poder Público para que se persigam os princípios constitucionais e thes dê concretude, os quais, invariavelmente, devem reger toda a completude das relações sócio-econômicas no Brasil.

Um de tais princípios é justamente o que pugna pela proteção e preservação do meio ambiente sadio e equilibrado, elevado ao nível constitucional em 1988, evidenciando a preocupação humana, que veio à tona nas últimas décadas do século $\mathrm{XX}$, com as nocivas conseqüências que 0 desenvolvimento industrial e o consumo desenfreados acarretam à saúde e à qualidade de vida dos indivíduos ao redor do globo. Ademais, o constituinte não olvidou de alocar a defesa do meio ambiente no rol dos princípios informadores da Ordem Econômica, insculpido que está no inciso VI do Art. 170, legitimando, com isto, todo agir estatal com vistas à sua efetividade.

Diante da constatação de que a qualidade do ar nas grandes cidades brasileiras é a cada dia pior, em maior medida devido ao grande e crescente número de veículos que nelas circulam, contribuindo para o aquecimento global e para que não se tenha um meio ambiente urbano sadio, impõe-se ao Estado que utilize de todos os meios para que o comando constitucional seja cumprido.

Impende, então, analisar a possibilidade de proceder a esta intervenção por meio da competência tributária, notadamente pela extrafiscalidade tributária. Esta competência pode ser exercida por meio de incentivos e, diante da análise ora promovida, pode-se sugerir ao Estado e ao Distrito Federal recorrer ao IPVA, instituindo-se alíquotas diferenciadas, conforme o grau de impacto ambiental que os veículos causam, ou seja, premiando com alíquotas menores aqueles que detêm a propriedade de veículos automotores que agridem menos o meio ambiente. 


\section{A competência estatal constitucional quanto à proteção do meio ambiente}

Em 1988, a questão que cinge a defesa e a preservação do Meio Ambiente foi erigida ao plano constitucional brasileiro. Alcançou este nível jurídico tendo em vista aos rumos da humanidade, sobretudo, no tocante à qualidade de vida das populações, ameaçadas pelos níveis de poluição do ar, da água, dos solos, pela degradação da fauna e flora, aquecimento da temperatura do planeta, etc. Exemplo desta crescente preocupação é a Declaração de Estocolmo, produzida durante a Conferência das Nações Unidas sobre 0 M eio Ambiente no ano de 1972 em que se afirmou logo no primeiro princípio, como direito fundamental dos homens, o meio ambiente de qualidade e com condições de vida adequadas.

Atento a este preceito e ao fato de que o Brasil ainda possui grandes reservas ambientais e, por via de conseqüência, grandes responsabilidades no que atine à sua preservação - como a Amazônia, para citar apenas um exemplo - o legislador constituinte dedicou um capítulo próprio ao M eio Ambiente (Capítulo Vl), que compõe o Título da Ordem Social brasileira (Título VII da Constituição Federal).

Insculpiu-se ali, no caput do Art. $225^{3}$, que o meio ambiente equilibrado é um direito de todos e essencial à sadia qualidade de vida, a partir de nítido traço de antropocentrismo, uma vez que a degradação do meio ambiente "compromete a possibilidade de uma existência digna para a humanidade e põe em risco a própria vida humana (MIRRA apud M ACHADO, 2008, p. 125)" ${ }^{\prime 4}$.

Neste sentido, Paulo Affonso Leme Machado destaca o fato do constituinte de 1988 não ter apenas criado o direito ao meio ambiente sadio, mas, indo muito além, vinculou tal direito com a sadia qualidade de vida dos indivíduos. Em complementariedade, ao comentar tal direito e, conseqüentemente, o direito à saúde humana, o referido professor assevera:

A saúde dos seres humanos não existe somente numa contraposição a não ter doenças diagnosticadas no presente. Leva-se em conta o estado dos elementos da Natureza - águas, solo, ar, flora, fauna e paisagem - para aquilatar se esses

\footnotetext{
${ }^{3}$ Art. 225. Todos têm direito ao meio ambiente ecologicamente equilibrado, bem de uso comum do povo e essencial à sadia qualidade de vida, impondo-se ao Poder Público e à coletividade o dever de defendê-lo e preservá-lo para as presentes e futuras gerações.

${ }^{4}$ Vale lembrar que este antropocentrismo é equilibrado com o biocentrismo trazido dos parágrafos do mesmo Art. 225 da Constituição, conforme leciona Leme Machado (2008, p. 125).
} 
elementos estão em estado de sanidade e se de seu uso advêm saúde ou doenças e incômodos para os seres humanos (M ACHADO, 2008, p. 128).

Estas constatações revelam-se importantes na medida em que fundamentam, constitucionalmente, o agir estatal no sentido da proteção e da preservação do meio ambiente equilibrado e sadio. Direito este que, como garantido a todos como bem de uso comum do povo, é direito difuso ou de terceira geração e, assinalada a sua importância para as gerações presente e futura, demanda do Estado a obrigação de promovê-lo, juntamente com a coletividade, no termos do caput do Art. 225. Em conformidade com este enunciado, o Art. 50, inciso LXXIII, outorga a qualquer cidadão legitimidade para propor ação popular que vise a anular ato lesivo ao meio ambiente, entre outros. ${ }^{5}$

Ao incumbir ao Poder Público o dever de defender e preservar o meio ambiente equilibrado, reputado como essencial à qualidade de vida, a Constituição não restringiu tal dever a um dos poderes da República. Tal compromisso deve ser perseguido não só pelo Executivo, mas também pelo Legislativo e Judiciário, no âmbito de suas competências.

Aliás, como bem ensina Marcelo Figueiredo (2005, p. 571), a análise do Art. 225, caput e incisos, revela o mais importante dos princípios do meio ambiente no direito brasileiro, que é o da obrigatoriedade da intervenção estatal. É a partir das ações determinadas pela Carta Magna que se pode caminhar no sentido de dar efetividade à almejada defesa do meio ambiente e da qualidade de vida sadia de que se falou. ${ }^{6}$

Neste quadro constitucional, em que o Estado deve preservar e controlar "as ações públicas e particulares que tenham algum potencial de dano ou prejuízo (TÔRRES, 2005, p. 98)", constata-se que esta competência não foi dada apenas à União. Trata-se, na verdade, de competência comum que se estende aos Estados, ao Distrito Federal e aos M unicípios, conforme prescreve o Art. 23 da Constituição, que traz entre seus incisos o comando de proteger o meio ambiente e combater a poluição em qualquer de suas formas, preservar as

\footnotetext{
${ }^{5}$ Art. 50, LXXIII - qualquer cidadão é parte legítima para propor ação popular que vise a anular ato lesivo ao patrimônio público ou de entidade de que o Estado participe, à moralidade administrativa, ao meio ambiente e ao patrimônio histórico e cultural, ficando o autor, salvo comprovada má-fé, isento de custas judiciais e do ônus da sucumbência;

${ }^{6}$ Como demais princípios do meio ambiente presentes na Constituição, Figueiredo (2005, p. 568-573) elenca, ainda, o do direito humano fundamental; supremacia do interesse público na proteção do meio ambiente em relação aos interesses privados; da indisponibilidade de o interesse público na proteção do meio ambiente; da prevenção ou precaução e do desenvolvimento sustentado.
} 
florestas, a fauna e a flora e registrar, acompanhar e fiscalizar as concessões de direitos de pesquisa e exploração de recursos hídricos e minerais em seus territórios ${ }^{7}$.

No Art. 24, tratando da competência legislativa concorrente, a Constituição afirmou, de forma expressa, que cabe a União, aos Estados e ao Distrito Federal legislar sobre as matérias pertinentes à proteção do meio ambiente sadio, vinculando tal competência relativamente às florestas, caça, pesca, fauna, conservação da natureza, defesa do solo e dos recursos naturais, proteção do meio ambiente e controle da poluição ${ }^{8}$.

Como se vê, a implementação de políticas públicas que visem à preservação do meio ambiente é tarefa conjunta e inarredável a ser realizada pelos entes federativos brasileiros e que não podem ser relegadas sob o argumento econômico de crescimento e desenvolvimento, até porque o constituinte cuidou de insculpir a defesa do meio ambiente como princípio basilar a reger as relações econômicas, conforme prevê o Art. 170 da Carta de 1988, que trata da Ordem Econômica Nacional, sobre o que se passa a discutir.

\section{Ordem econômica nacional e meio ambiente}

O Art. 170 da Constituição, que inaugura o Título da Ordem Econômica Nacional, estabelece como sua pedra fundamental a valorização do trabalho humano e a livre iniciativa e como seu objetivo assegurar a todos a existência digna, conforme os ditames da justiça social. Em seguida, nos incisos do referido dispositivo, estão elencados seus princípios informadores, os quais devem nortear as relações econômicas no Brasil e, portanto, legitimam a intervenção estatal no sentido de promover a efetividade de tais princípios. São eles: soberania nacional, propriedade privada, função social da propriedade, livre concorrência, defesa do consumidor, defesa do meio ambiente, redução das desigualdades regionais e sociais, busca do pleno emprego e tratamento favorecido para as empresas de pequeno porte.

\footnotetext{
${ }^{7}$ Art. 23. É competência comum da União, dos Estados, do Distrito Federal e dos M unicípios:

$\mathrm{VI}$ - proteger o meio ambiente e combater a poluição em qualquer de suas formas;

VII - preservar as florestas, a fauna e a flora;

XI - registrar, acompanhar e fiscalizar as concessões de direitos de pesquisa e exploração de recursos hídricos e minerais em seus territórios;

${ }^{8}$ Art. 24. Compete à União, aos Estados e ao Distrito Federal legislar concorrentemente sobre:

$\mathrm{VI}$ - florestas, caça, pesca, fauna, conservação da natureza, defesa do solo e dos recursos naturais, proteção do meio ambiente e controle da poluição;

VIII - responsabilidade por dano ao meio ambiente, ao consumidor, a bens e direitos de valor artístico, estético, histórico, turístico e paisagístico.
} 
Conforme exposto, o constituinte foi cuidadoso ao alocar a defesa do meio ambiente quando da tratativa da ordem econômica, afastando qualquer pretensa alegação de que desenvolvimento econômico e consciência ambiental não se coadunam. Foi-se além em 2003, quando a Emenda Constitucional acrescentou ao inciso VI do Art. 170, que corresponde ao princípio da defesa do meio ambiente, a seguinte redação: inclusive mediante tratamento diferenciado conforme 0 impacto ambiental dos produtos e serviços e de seus processos de elaboração e prestação.

Não se pode relacionar a regulação da atividade econômica e a defesa do meio ambiente sem lançar mão do princípio do desenvolvimento sustentável. Deve-se buscar a compatibilização entre desenvolvimento e crescimento econômico com preservação ambiental e, consequentemente, com desenvolvimento social e humano, todos albergados pelo desenvolvimento nacional a que se refere o Art. 3ำ, inciso II, da Lei Maior, que estatui os objetivos da República.

E esta compatibilização é fruto da interpretação que deve ser dada ao texto constitucional diante de princípios que dotam, os atores econômicos, de plenas capacidades na aferição de seus resultados e lucros, como a livre iniciativa e a livre concorrência, e princípios que, teoricamente, trariam limitações ou "freariam" o pleno desenvolvimento, como a função social da propriedade e a aludida questão ambiental. Neste ponto, emprestam-se as constatações de M aria de Fátima Ribeiro e Jussara Nasser Ferreira:

[...] em que pese a exigência constitucional de respeito pelo meio ambiente, a atividade empresarial, em grande escala, desconsidera os efeitos nocivos de determinadas ações, que podem provocar danos ao meio ambiente. É pertinente observar que a livre iniciativa não pressupõe irresponsabilidade por prejuízos causados à natureza e à comunidade. 0 artigo 30 da Constituição Federal, através do inciso II, assegura que o Estado deve garantir o desenvolvimento. E ao garantir 0 desenvolvimento, deve promover a combinação de crescimento econômico com as condições básicas de vida, dentre as quais a alimentação, a saúde e preservação ambiental (RIBEIRO; FERREIRA, 2005, p. 656).

Pode-se depreender, a partir destas breves considerações, que a busca pelo desenvolvimento proposto pela Constituição - do qual o crescimento econômico é um dos componentes - não pode afastar a preocupação com o meio ambiente e com a qualidade de vida de toda a comunidade. Em verdade, meio ambiente e desenvolvimento são complementares, "pois não há desenvolvimento sem proteção ao meio ambiente, e o meio 
ambiente equilibrado faz com que o homem alcance um grau de desenvolvimento satisfatório (ALM EIDA apud RIBEIRO; FERREIRA, 2005, p. 656)".

Almejar o desenvolvimento sustentável é buscar o crescimento econômico sim, explorando inclusive recursos naturais, mas de uma forma racional, sem comprometê-los, e visando sempre à promoção da qualidade de vida do homem, a partir da vivência em um meio ambiente equilibrado, sadio, mais uma vez insistindo nas expressões que brotam do comando constitucional. 0 agente econômico, seja público ou privado, tem o direito de atuar livremente no mercado nacional, como Ihe garante a M agna Carta. Porém, nesta tutela não está incluída a possibilidade de usurpar o meio ambiente nacional.

\section{Intervenção sobre o domínio econômico}

De acordo com Pimenta (2002, p. 39), podem ser percebidas no texto constitucional duas formas de intervenção do Estado sobre o domínio econômico: uma direta e outra indireta ${ }^{9}$. A primeira delas encontra previsão no Art. 173 (exploração direta de atividade econômica pelo Estado, nos termos do citado dispositivo) e volta-se ao agir do Estado como um dos entes empresários privados que atuam no mercado nacional por meio de operações mercantis, trocas de mercadorias, etc. Diz-se que o Estado atua como um ente privado, pois o $§ 10$ do mesmo Art. 173 determina justamente que, nestes casos, o regime jurídico será o de direito privado e não público. Esta prescrição é explicável na medida em que, se detivesse posição privilegiada, não poderia concorrer de forma leal com os demais agentes privados que movem a economia nacional.

Ainda sobre a intervenção direta, o caput do Art. 173 estabelece sua jaez de excepcionalidade, haja vista ser permitida, para encontrar lastros constitucionais, apenas quando verificados os imperativos da segurança nacional ou relevante interesse coletivo,

\footnotetext{
${ }^{9}$ Eros Grau (2006, p. 95) sugere que o termo intervenção deveria ser usado apenas nos casos em que o Estado age em seara que seja de titularidade do setor privado, que seriam aqueles do Art. 173 da CF; já para o caso de ação estatal voltada tanto para área de titularidade do setor privado como do próprio Estado (concessões, por exemplo), o termo deveria ser atuação estatal, como nos casos trazidos pelo Art. 174 (regulação e normatização por meio de planejamento, fiscalização e incentivo). Apesar deste ensaio não adotar esta nomenclatura, deve-se ficar consignado que o comando do Art. 174, como assevera o ministro do STF, não se restringe apenas à seara privada, mas também à pública.
} 
assim definidos em lei. ${ }^{10}$ Outra hipótese seriam os monopólios de exploração de determinados setores outorgados à União pelo Art. $177^{11}$ ou Art. 21, XXIII ${ }^{12}$ da Constituição. Eros Grau classifica estas formas de intervenção como participação (nos casos em que o ente público co-existe com agentes privados) e absorção (no caso dos monopólios) (GRAU, 2006, p. 148-149).

Quanto à intervenção indireta, encontra-se ela estabelecida no Art. 174 da Carta da República e tem como traço caracterizador o agir do Estado como agente normativo e regulador. Tal atuação normativa e regulatória se dá por meio do exercício de três funções próprias do Estado: fiscalização, incentivo e planejamento. 0 Estado, neste caso, visando ao atendimento dos fins constitucionais a que está vinculado, atua como agente externo às relações econômicas, sobre elas.

Cumpre lembrar que os papéis de normatizar e regular a ordem econômica nacional não se confundem. Paulo Henrique Rocha Scott (2000, p.110) aponta que, no tocante à normatização, a Constituição autoriza o Estado a criar disposições normativas com vistas a dar concretude "aos valores, princípios, preceitos e objetivos que conformam a ordem econômica constitucional, criando um espaço normativo infraconstitucional contentor das diretrizes mais específicas e práticas (...)". Já no âmbito da atividade reguladora, o Estado

\footnotetext{
${ }^{10}$ Art. 173. Ressalvados os casos previstos nesta Constituição, a exploração direta de atividade econômica pelo Estado só será permitida quando necessária aos imperativos da segurança nacional ou a relevante interesse coletivo, conforme definidos em lei.

${ }^{11}$ Art. 177. Constituem monopólio da União:

I - a pesquisa e a lavra das jazidas de petróleo e gás natural e outros hidrocarbo netos fluidos;

II - a refinação do petróleo nacional ou estrangeiro;

III - a importação e exportação dos produtos e derivados básicos resultantes das atividades previstas nos incisos anteriores;

IV - o transporte marítimo do petróleo bruto de origem nacional ou de derivados básicos de petróleo produzidos no País, bem assim o transporte, por meio de conduto, de petróleo bruto, seus derivados e gás natural de qualquer origem;

$V$ - a pesquisa, a lavra, o enriquecimento, o reprocessamento, a industrialização e o comércio de minérios e minerais nucleares e seus derivados, com exceção dos radioisótopos cuja produção, comercialização e utilização poderão ser autorizadas sob regime de permissão, conforme as alíneas b e c do inciso XXIII do caput do art. 21 desta Constituição Federal.

(...).

12 Art. 21. Compete à União:

$(\ldots)$;

XXIII - explorar os serviços e instalações nucleares de qualquer natureza e exercer monopólio estatal sobre a pesquisa, a lavra, o enriquecimento e reprocessamento, a industrialização e 0 comércio de minérios nucleares e seus derivados, atendidos os seguintes princípios e condições: (...).
} 
busca efetivar estas normas já positivadas, quando do exercício da função normativa, submetendo as situações fáticas aos comandos legais.

E sobre o exercício destes papéis por meio da fiscalização, incentivo e planejamento, Eros Grau leciona com propriedade, entrelaçando tais ações:

A atuação normativa reclama fiscalização que assegure a efetividade e eficácia do quanto normativamente definido [...]. A atuação reguladora há de, impõe a Constituição, compreender 0 exercício das funções de incentivo e planejamento. Mas não apenas isso: atuação reguladora reclama também fiscalização e, no desempenho de sua ação normativa, assinala, como funções que Ihe atribui, as de incentivo e planejamento. Este, por outro lado, não abrange apenas a atividade econômica em sentido estrito, porém toda atividade econômica em sentido amplo (GRAU, 2006, p. 109).

As distorções e desvios havidos no âmbito das relações econômicas, relativamente aos princípios e preceitos legais previamente estabelecidos para regê-las, devem ser combatidos pelo Poder Público, a partir de procedimentos fiscalizatórios capazes de desvendá-los à sociedade para que sejam corrigidos. Neste quadro é que se legitima a criação de instituições públicas dotadas de poder para procederem a estas verificações de compatibilidade entre os agentes econômicos e suas ações com as normas jurídicas que encerram a Ordem Econômica Nacional. É, em poucas linhas, esta a função de fiscalização ${ }^{13}$ encetada na Lei Maior, Art. 174.

Já por meio do Planejamento - que é determinante para o setor público e apenas indicativo ao privado - o Estado age prevendo "comportamentos econômicos e sociais futuros", formulando, explicitamente, objetivos e definindo "meios de ação coordenadamente dispostos", como sumariza Eros Grau (2006, p. 348). Revela, pois, como traço característico, uma "visão prospectiva", própria de uma constituição dirigente, ainda segundo as lições de Grau.

0 ilustre professor assevera, além disso, que o planejamento não pode ser classificado como uma modalidade de intervenção estatal em razão de que o planejamento implica a formulação de políticas públicas, de objetivos-fins, constituindo-se como um

${ }^{13}$ No que atine à questão da proteção ambiental, a fiscalização das relações econômicas, pela própria complexidade que estampa, dá-se pela confluência de vários setores da esfera política (Competências comum e concorrentes, conforme Arts. 23 e 24 da CF, já assinalados anteriormente). Assim, por exemplo, 0 SISNAMA - Sistema Nacional do Meio Ambiente - instituído pela Lei 6.938/1981, é constituído pelos órgãos e entidades da União, dos Estados, do Distrito Federal, dos Municípios e pelas Fundações instituídas pelo Poder Público. 
método que qualifica a intervenção, tornando-a "sitematizadamente racional" (GRAU, 2006, p. 151).

A própria Constituição Federal refere-se a planejamento em vários momentos, os quais podem servir de exemplo, neste ponto: 0 Art. 21, IX, atribui à União executar "planos nacionais e regionais de ordenação do território e de desenvolvimento econômico e social"; o Art. 30, VII, impõe ao M unicípio a tarefa de promover o adequado ordenamento territorial, por meio de planejamento do solo urbano e elaborar o Plano Diretor (obrigatoriamente aos municípios com mais de vinte mil habitantes); 0 Art. 48, II, atribui o dever ao Congresso Nacional de dispor sobre o Plano Plurianual, etc.

Já o incentivo, de seu turno, enquadra-se nos moldes da intervenção por indução, postulada por Grau, diferentemente das intervenções por direção e por absorção ou participação. Estas duas últimas - absorção e participação - correspondem à atuação estatal de forma direta na seara econômica, respectivamente, por monopólio ou competindo com os demais atores privados, sobre o que já se comentou acima; seriam hipóteses de intervenção no domínio econômico. A intervenção por direção seria aquela dotada de compulsoriedade, em que o Estado estatui comportamentos, cuja obediência é obrigatória aos entes econômicos e, juntamente com a intervenção por indução, classifica-se como intervenção sobre o domínio econômico (GRAU, 2006, p. 148-149).

0 que diferencia a direção da indução é que nesta o "Estado manipula os instrumentos de intervenção em consonância e na conformidade das leis que regem o funcionamento dos mercados (GRAU, 2006, p. 149)". Dito de outra forma, não há obrigatoriedade na determinação dos comportamentos almejados pelo Poder Público, mas sim, estabelecem-se estímulos convidativos aos particulares que atuam no campo econômico para que façam parte de determinada política perseguida pelo Estado. Ao induzir, não há comando, mas sim convite, chamamento, que pode ser recusado por aqueles a quem se dirige. Note-se:

Ao destinatário da norma resta aberta a alternativa de não se deixar por ela seduzir, deixando de aderir à prescrição nela veiculada. Se adesão a ela se manifestar, no entanto, resultará juridicamente vinculado por prescrições que correspondem aos benefícios usufruídos em decorrência dessa adesão. Penetramos, aí, 0 universo do direito premial. A sedução à adesão ao comportamento sugerido é, todavia, extremamente vigorosa, dado que os agentes econômicos por ela não tangidos passam a ocupar posição desprivilegiada nos 
mercados. Seus concorrentes gozam, porque aderiram a este comportamento, de uma situação de donatário de determinado bem, [...] o que lhes confere melhores condições de participação naqueles mesmos mercados (GRAU, 2006, p. 150).

Enfatiza-se a intervenção por indução por ser em seus moldes que se enquadra 0 incentivo estabelecido no Art. 174 da Carta Magna. Traz consigo, portanto, a idéia de ação suasória e não compulsória por parte do Estado, visando a que os entes econômicos adotem determinado comportamento econômico ${ }^{14}$, conveniente a toda sociedade, seguindo os parâmetros desenhados pela Constituição Federal em toda a sua extensão, mas, principalmente, no capítulo próprio da Ordem Econômica Nacional. Vale dizer, a intervenção estatal por meio do incentivo há de se arrimar nos princípios informadores da Ordem Econômica pretendida constitucionalmente, buscando sempre a concretude de seus objetivos.

0 incentivo se viabiliza, aponta Scott (2000, p. 126), na criação de subsídios econômicos a dados produtos; nos financiamentos favorecidos, em que se estimula 0 desenvolvimento de um determinado setor, como o agrícola ou o habitacional; no investimento em infra-estrutura, de nítido cunho financeiro, ou até na disponibilização de assistência tecnológica e, principalmente, na instituição de incentivos fiscais, como a criação de alíquotas diferenciadas de impostos.

Neste passo, atinge-se um ponto nodal do presente trabalho, haja vista buscar ele justamente lançar mão deste expediente de intervenção (por meio do incentivo, da indução) para atingir os desideratos constitucionais relativos à proteção e à preservação do meio ambiente sadio e equilibrado, garantindo a todos qualidade de vida, essencial para a existência humana e para o desenvolvimento da sociedade brasileira. Desenvolvimento este entendido, repita-se, não apenas em termos econômicos, mas considerando-se todos os seus prismas, inclusive o econômico, e principalmente o humano.

\footnotetext{
${ }^{14} \mathrm{~A}$ intervenção por meio de incentivos não se restringe a induções positivas, podendo também adquirir caráter de negatividade, em que, apesar de não se proibir uma ação, criam-se barreiras de modo que a ação se torna muito desvantajosa ao agente econômico. 0 Estado, em suma, desestimula certos comportamentos (GRAU, 2006, p. 150; SCOTT, 2000, p. 127).
} 


\section{Incentivo e extrafiscalidade}

A partir do recorte temático proposto, a atuação indutiva do Estado sobre o Domínio Econômico utilizando-se de sua competência tributária via extrafiscalidade, por meio do Imposto sobre a Propriedade de Veículo Automotor, pode ser aproveitada no intuito de efetivar os objetivos constitucionais de defesa do meio ambiente, notadamente naquilo que envolve a qualidade de vida em sociedade.

Forçoso é perscrutar na doutrina pátria o conceito de extrafiscalidade tributária e por quê ela deve ser usada para fins de proteção do meio ambiente para, posteriormente, analisar a possibilidade de sua implementação no caso Imposto sobre Propriedade de Veículo Automotor, bem como as justificativas para tanto.

Com o apoio das sempre precisas lições de Paulo de Barros Carvalho, a extrafiscalidade pode ser conceituada como uma "forma de manejar elementos jurídicos usados na configuração dos tributos, perseguindo objetivos alheios aos meramente arrecadatórios (CARVALHO, 2006, p. 253)". Busca-se, por meio da competência tributária, alcançar metas prevalecentes em relação à simples arrecadação de dinheiro aos cofres públicos.

Não se pode deixar de citar o ilustre Roque Antônio Carrazza (2008, p. 688), que explica com clareza que a noção de tributo como instrumento de arrecadação de recursos foi aperfeiçoada pela "idéia de que ele pode e deve ser utilizado para favorecer a realização dos mais elevados objetivos sociais, econômicos e políticos".

Se é assim, o legislador, ao implementar esta ação extrafiscal, deve, inexoravelmente, respeitar os delineamentos constitucionais afetos ao sistema tributário, sobretudo no que atine às limitações de competência e aos princípios basilares do referido sistema, conforme aponta Carvalho (2006, p. 254). No mesmo sentido, Carrazza (2008, p. 688) condiciona a legitimidade da intervenção por meio do incentivo (extrafiscalidade) a que os contribuintes não sejam impedidos de manter suas atividades econômicas lícitas ou suas riquezas não sejam esgotadas, o que se mostraria como típico traço de confisco.

0 professor Carrazza aduz ainda que não existem dispositivos que estabelecem a extrafiscalidade dos tributos de modo expresso na Constituição. Todavia, esta faculdade do Estado nela está presente implicitamente, ao atribuir-se ao Poder Público o dever de promover os objetivos da República, entre os quais se pode citar a proteção ao meio 
ambiente. Na dicção do aludido professor da PUC-SP, "a Constituição, ao estatuir, por exemplo, (...) que 'todos têm direito ao meio ambiente ecologicamente equilibrado (art. 225)', (...), indiretamente obriga que os tributos sejam ajustados a estes louváveis objetivos (...)(2008, p. 689)", incluindo-se neste contexto a defesa do meio ambiente por meio de tratamento diferenciado conforme 0 impacto ambiental dos produtos e serviços e de seus processos de elaboração e prestação, conforme reza o Art. 170, VI do Código M agno.

Fortalece a idéia de se usar a extrafiscalidade dos tributos a constatação de que 0 sistema constitucional vigente não deixa espaços para a criação de novos tributos, como um "imposto ecológico", por exemplo, a não ser no caso de exercício da competência residual da União, prevista no Art. 154, I, da Constituição. Ademais, por força do Art. 167, IV, não se poderia criar fundos ligados aos impostos já existentes, segundo Taveira Tôrres (2005, p. 109).

Outrossim, Regina Helen Costa (2005, p. 322) afirma que o princípio da capacidade contributiva previsto no Art. 145, § 1 o da Constituição, convive, perfeitamente, com a extrafiscalidade dos tributos, em razão da qual, nas palavras da autora, "autorizada está a prescindibilidade da graduação dos impostos consoante a capacidade econômica do contribuinte, para que se atinjam finalidades outras, (...) homenageadas pela ordem constitucional". No caso do IPVA, aliás, nem se poderia levantar argumento contrário, pois, como se sabe, as alíquotas estabelecidas pelos Estados não são diferenciadas em função da capacidade contributiva, a partir dos valores venais.

Tampouco se poderia arrazoar contrariamente ao uso extrafiscal do IPVA pela alegação de que violaria o princípio da igualdade. Sobre isto, Humberto Ávilla lembra, embasando-se em reiterada jurisprudência do Supremo Tribunal Federal, que não se contraria a igualdade ao se outorgar finalidade extrafiscal ao tributo, desde que 0 tratamento diferenciado dado pela norma i) seja igual aos contribuintes de igual situação; ii) não viole qualquer dos direitos fundamentais; iii) justifique-se em um fundamento constitucional e iv) o igual tratamento não implicasse nenhuma pretensão (ÁVILA, 2008, p. 352). 


\section{Alíquotas seletivas de IPVA em função do impacto ambiental causado pelos veículos: uma medida que se impõe.}

Não faltam razões para que sejam instituídas alíquotas de IPVA seletivas de acordo com o grau de poluição dos veículos, utilizando-se do expediente da indução por incentivos fiscais. Pelo contrário, elas existem e são muito fortes, o que demanda urgência na tomada de decisões, sempre visando à proteção do meio ambiente sadio e à saúde e qualidade de vida da população, garantias constitucionais que são, conforme se comentou acima.

Inúmeros estudos convergem para este entendimento, comprovando a nocividade que a poluição veicular apresenta para os sujeitos que vivem, mormente, nas grandes cidades do país. Esta nocividade advém dos gases tóxicos que são emitidos pelos veículos, principalmente: monóxido de carbono (CO), óxidos de nitrogênio (NOx), hidrocarbonetos $(H C)$, óxidos de enxofre $(S O x)$, material particulado $(M P)$, entre outros. Segundo a Companhia Ambiental do Estado de São Paulo (CETESB) ${ }^{15}$, que mantém informações sobre a qualidade do ar nas cidades paulistas em sua página virtual, são justamente estes elementos que servem de parâmetro para se aferir a qualidade do ar em todo o mundo.

A poluição do ar nas cidades decorre principalmente das emissões veiculares. Isto porque, conforme observação feita no "Relatório da Qualidade do $\operatorname{Ar}$ na Região Metropolitana de Curitiba - Ano 2008", da Secretaria de Estado de Meio Ambiente e Recursos Hídricos do Paraná (SEM A-PR) e do Instituto Ambiental do Paraná (IAP), ao serem comparadas as emissões veiculares com as industriais:

Primeiro, o número de veículos é muito maior do que o número de indústrias. É sempre mais difícil controlar um grande número de pequenos poluidores do que controlar alguns grandes poluidores. Segundo, muitas indústrias estão localizadas fora dos perímetros urbanos e lançam as emissões através de chaminés na atmosfera, com certa distância da população, enquanto os veículos liberam os poluentes geralmente nos centros urbanos, praticamente numa altura que possibilita a inalação direta pelos seres humanos. Logo, temos a convicção de que para melhorar a qualidade do ar nas cidades devemos nos concentrar com prioridade nas emissões veiculares (PARANÁ, 2008, p. 12, grifo nosso).

Este contato direto da população com os gases tóxicos veiculares de que se fala no referido Relatório traz conseqüências extremamente negativas à saúde dos indivíduos. Por

\footnotetext{
${ }^{15}$ www.cetesb.sp.gov.br
} 
exemplo, o material particulado (MO) que pode penetrar nas defesas do organismo, atingir os alvéolos pulmonares e causar desde mal-estares e irritações nos olhos e na garganta até bronquite, asma e câncer de pulmão. Sem falar no grande incômodo e stress que a fumaça causa aos pedestres e motoristas, juntamente com a redução do oxigênio no sangue em função da inalação de monóxido de carbono (MC).

A Organização Pan-Americana da Saúde, vinculada à ONU, e o Ministério da Saúde do Brasil informam (BRASIL, 2008, p. 21) que várias pesquisas indicam que está ocorrendo significativo aumento dos riscos associados às doenças respiratórias e cardiovasculares e da mortalidade ligada aos poluentes atmosféricos. E mais: "Segundo a OMS, 50\% das doenças respiratórias crônicas e $60 \%$ das doenças respiratórias agudas estão associadas à exposição a poluentes atmosféricos".

Este preocupante quadro tende a se agravar ainda mais, a julgar pela frota veicular que cresce a cada ano. No Paraná, segundo dados do Departamento de Trânsito (DETRANPR, Coordenadoria de Veículos) ${ }^{16}$, de janeiro de 2007 a janeiro de 2009, houve um aumento de $18,66 \%$ na frota veicular do Estado, alcançando a marca de 4.382 .527 veículos automotores. No mesmo período, em todo o Estado de São Paulo, o acréscimo foi de 16,37 \%; somente a capital paulista conta com 6.396.088 veículos, como se pode notar nas informações oficiais do DETRAN-SP ${ }^{17}$.

Diante desta situação, algumas medidas vêm sendo tomadas. Já em 1979 foi desenvolvido pelo governo federal o PROALCOOL - Programa Nacional do Álcool, que estimulou, ao longo da década de 80 e 90, alterações na composição dos combustíveis, culminando na chegada dos bicombustíveis ao mercado de automóveis e na busca pelo desenvolvimento de biocombustíveis. Também se estimulou a conversão de veículos movidos a álcool, diesel e gasolina para o gás natural veicular (GNV). No Paraná, inclusive, instituiu-se alíquota menor para veículos que funcionam à base deste combustível. ${ }^{18}$ No entanto, a adesão foi baixa. No início de 2009, havia apenas cerca de 27.000 veículos

\footnotetext{
${ }^{16}$ www.detran.pr.gov.br

17 www.detran.sp.gov.br

18 Lei no. 14.260/2003: Art. 4ำ- As alíquotas do IPVA são:

I - 1\% (um por cento) para:

(...),

c) veículos automotores que utilizem o Gás Natural Veicular (GNV).

A alínea "c" foi acrescida pelo art.ํㅜㅇㅡ da Lei 14.505 de 23.09.2004.

(...).
} 
convertidos, número que pode ser explicado pela escassez de gás no mercado nacional, dependente que é o Brasil da Bolívia, neste quesito, destacada a instabilidade política e econômica do país andino.

Merece destaque a recente ação do M inistério do M eio Ambiente brasileiro. Em 1으 de dezembro de 2009, publicou em seu site na internet um ranking intitulado "Nota Verde", contendo 400 modelos de veículos fabricados em 2009, os quais são classificados com estrelas, de uma a cinco, de acordo com o nível de poluição que emitem. Quanto mais estrelas, mais eficiente e menos nocivo ao ambiente é o veículo. 0 ministro da pasta, Carlos M inc, justifica a medida: "O objetivo da Nota Verde é orientar o consumidor. Queremos que o consumo consciente cresça cada vez mais, e que assim seja criada uma concorrência positiva entre as montadoras, para que produzam carros mais eficientes", conforme nota da Assessoria de Comunicação do M MA, de 01/12/2009. ${ }^{19}$

Como se pode notar existem parâmetros e meios para se aferir, tecnicamente, 0 grau de poluição dos automotores que circulam atualmente pelas vias públicas. Um passo adiante deve ser dado, que é justamente a criação de alíquotas diferenciadas de IPVA com base na emissão de poluentes de cada modelo, que é o objetivo defendido pelo presente trabalho.

O Imposto sobre Propriedade de Veículos Automotores tem prescrição constitucional no Art. 155, $\mathrm{II}^{20}$, e figura entre os tributos de competência dos Estados e do Distrito Federal. Esta competência é, em verdade, plena, haja vista a inexistência de lei federal sobre normas gerais, o que autoriza os Estados a editarem leis que se façam necessárias à aplicação do sistema tributário, conforme se pode depreender da análise

\footnotetext{
${ }^{19}$ www.mma.gov.br

${ }^{20}$ Art. 155. Compete aos Estados e ao Distrito Federal instituir impostos sobre:

(...)

III - propriedade de veículos automotores.

(...).

$\S 600$ imposto previsto no inciso III:

I - terá alíquotas mínimas fixadas pelo Senado Federal;

II - poderá ter alíquotas diferenciadas em função do tipo e utilização.
} 
conjunta dos Art. $24, \S 30$ da Constituição ${ }^{21}$ e 34, § 30 do Ato das Disposições Constitucionais Transitórias ${ }^{22}$.

No exercício de tal competência, o Estado está autorizado pelo § 60 do Art. 155 da Constituição Federal a estabelecer alíquotas diferenciadas "em função do tipo e utilização", cuja redação adveio com a Emenda Constitucional n‥ 42/2003 e em cujo interior se insere, certamente, a seleção de alíquotas com arrimo no nível de poluição de cada automotor sobre o qual incide o tributo. Diante do bem ambiental é essencial tratar de modo diferente os diferentes graus de impacto, conforme dispõe a parte final da norma do Art. 170, VI da CF.

Infelizmente, os Estados-membros, movidos pela cupidez arrecadatória, têm se esquivado de sua responsabilidade constitucional de defender o meio ambiente, sem se utilizarem do expediente da extrafiscalidade do IPVA, conquanto assaz eficiente pode ele se tornar para reduzir a emissão de gases poluentes na atmosfera não só das cidades mas de todo o Planeta.

Ao comentar a determinação contida no Art. 170, VI da Constituição de se dispensar "tratamento diferenciado conforme o impacto ambiental", o professor Roque Antônio Carrazza leciona:

As citadas normas constitucionais e outras da mesma índole são de aplicação efetiva, e não, como querem alguns, meros programas de ação, a serem - um dia desenvolvidos e implementados. De conseguinte, impõem aos Poderes Públicos 0 dever de prestigiá-las de todas as formas, inclusive na tributação (CARRAZA, 2008, p. 690).

Um exemplo da omissão dos Estados quanto a este dever de proteger o meio ambiente por meio da tributação, em se tratando da redução de poluentes emitidos pelos veículos automotores, é o Paraná. Aliás, além de não estimular os proprietários na aquisição de transportes mais limpos e menos nocivos à sociedade, concede isenção do imposto aos proprietários de veículos com mais de 20 anos $^{23}$. Ora, são justamente os mais antigos -

${ }^{21}$ Art. 24, § 3o da CF - Inexistindo lei federal sobre normas gerais, os Estados exercerão a competência legislativa plena, para atender a suas peculiaridades.

${ }^{22}$ Art. 34, § 30 do ADCT - Promulgada a Constituição, a União, os Estados, o Distrito Federal e os Municípios poderão editar as leis necessárias à aplicação do sistema tributário nacional nela previsto.

23 Lei 14.260/2003: Art. 14. São isentos do pagamento do IPVA, os veículos automotores: (...) 
posto que produzidos com tecnologia menos avançada, além do desgaste dos motores com o tempo, que corroboram de forma mais incisiva para a poluição atmosférica. Este mesmo padrão é seguido pelos Estados de São Paulo (Art. 13, VIII da Lei n013.296/2008); Rio Grande do Sul (Art. 4ํㅗ, IV da Lei no 8.115/1985); Santa Catarina (Art. 8o, V, ' $f$ '); Rio de Janeiro (Art. 5으, VII da Lei ํ․ 2.877/1997, fabricados a mais de 15 anos), entre outros.

Posturas diametralmente opostas a estas urgem ser adotadas, dada a importância do tema e em consideração aos pontos que se alinhavaram no decorrer deste trabalho. Com efeito, impõe-se a fixação de alíquotas menores aos que menos poluem para que se atenda a ordem constitucional de proteger o meio ambiente, mantendo-o sadio e garantindo qualidade de vida dos cidadãos brasileiros.

\section{Considerações finais}

No texto constitucional de 1988, tem-se a competência garantida aos governos, para intervir nas relações econômicas em favor da realização do Regime Jurídico Econômico (Art. 170). Este conjunto de valores e normas dirige-se aos governos, os agentes econômicos e a sociedade em geral. Desta forma, para promover a efetividade deste regime jurídico deve-se advogar a ação conjunta dos seus destinatários, uma vez que, as relações humanas no plano econômico têm especial interesse para o Estado brasileiro, tendo sido elevado ao nível de patrimônio nacional (Art. 219).

Os governos podem intervir neste domínio por meio normativo, fiscalizador, incentivador e de planejamento. Nesta pesquisa destacou-se a norma constitucional da defesa do meio ambiente (Art. 170, VI), a intervenção indireta por meio das normas de incentivo de conteúdo tributário (Art. 174), especificamente pela seletividade possível de ser utilizada no IPVA (Art. 155,§ 60) ), para veículos movidos por combustível de menor impacto ambiental. Desta forma estar-se-á positivando a determinação constitucional de tratamento diferenciado de bens conforme o impacto ambiental (Art. 170,VI, parte final).

A opção da extrafiscalidade se deve para possibilitar a convivência harmônica com outros princípios da ordem jurídico econômica: a livre iniciativa e a livre concorrência. Assim, por meio das normas de incentivos pode-se atingir de modo mais efetivo a racionalidade

IX - com mais de 20 anos de fabricação.

(...). 
econômica que é movida pelo valor eficiência, ou seja, ao tributar com menor carga tributária pretende-se estimular a produção e consumo de veículos de menor potencial poluidor. Este caminho favorece a livre iniciativa e os ótimos efeitos de um mercado concorrencial, tais como, os investimentos em tecnologias energéticas ambientalmente adequadas. São as diretrizes para o desenvolvimento econômico sustentável, que certamente promove ganho em qualidade na vida para todos.

\section{Referências}

ÁVILA, Humberto. Sistema Constitucional Tributário. 3 ed. rev. e atual. São Paulo: Saraiva, 2008.

BRASIL, M inistério da Saúde. M udanças Climáticas e Ambientais e seus efeitos na Saúde: Cenários e Incertezas para o Brasil. Brasília: Organização Pan-Americana da Saúde, 2008.

CARRAZZA. Roque Antônio. Curso de Direito Constitucional Tributário. 24. ed. rev. ampl. atual. São Paulo: Malheiros Editores, 2008.

CARVALHO, Paulo de Barros. Curso de Direito Tributário. 19. ed. rev. São Paulo: Saraiva, 2007.

FIGUEIREDO, Marcelo. A Constituição e o M eio Ambiente: os princípios constitucionais aplicáveis à matéria e alguns temas correlatos. In: TÔRRES, Heleno Taveira (Org.). Direito Tributário Ambiental. São Paulo: M alheiros Editores, 2005.

GRAU, Eros Roberto. A Ordem Econômica na Constituição de 1988. 11. ed. rev. atual. São Paulo: M alheiros Editores, 2006.

M ACHADO, Paulo Affonso Leme. Direito Ambiental Brasileiro. 16. ed. São Paulo: M alheiros Editores, 2008.

PARANÁ, Instituto Ambiental do Paraná. Relatório da Qualidade do Ar na Região Metropolitana de Curitiba. Ano 2008.

PIM ENTA, Paulo Roberto Lyrio. Contribuições de Intervenção no Domínio Econômico. São Paulo: Dialética, 2002.

RIBEIRO, Maria de Fátima; FERREIRA, Jussara S. A. B. Nasser. O Papel do Estado no Desenvolvimento Econômico Sustentável: Reflexões sobre a Tributação Ambiental como Instrumento de Políticas Públicas. In: TÔRRES, Heleno Taveira (Org.). Direito Tributário Ambiental. São Paulo: Malheiros Editores, 2005. 
SCOTT, Paulo Henrique Rocha. Direito Constitucional Econômico: Estado e Normalização da Economia. Porto Alegre: Sérgio Antônio Fabris Editor, 2000.

TÔRRES, Heleno Taveira. Da Relação entre Competências Constitucionais Tributária e Ambiental - Limites dos chamados "Tributos Ambientais". In: TÔRRES, Heleno Taveira (Org.). Direito Tributário Ambiental. São Paulo: M alheiros Editores, 2005. 